\title{
MÉTHODES ACTUELLES DE DÉTECTION POUR LA BACTÉRIOLOGIE ET AUTRES MICROORGANISMES DANS LES EAUX
}

\author{
Microbiologie et Eau, Parasites, Virus, Fungi et eau \\ Méthodes Classiques. Détection rapide, Méthode PCR, CPG \\ Comparaison de méthodes et de résultats. \\ Eaux Récréatives. Piscines : dont piscines thermales. Spa. Eaux potables ...
}

\section{Editorial}

\section{Thèmes du colloque}

\section{THEME I : LE POINT SUR LES ÉVOLUTION RÉCENTES DE DÉTECTION ET DE QUANTIFICATION EN MICROBIOLOGIE DES EAUX.}

Ce colloque, réunissant des experts concernés par cette problématique et appartenant à des domaines variés (hydrologie, contrôle sanitaire, traitement d'eau, microbiologie, thermalisme, industriels, etc.), se fixe comme objectif de faire le point sur les méthodes modernes en bactériologie des eaux, en présentant leurs avantages en matière de rapidité et de facilités de mises en œuvre.

La notion de microbiologie est prise au sens large avec notamment les bactéries, les parasites, les virus recherchés dans les eaux qu'elles soient d'alimentation, de surface, récréatives, de piscines publiques ou privées, ou des piscines thermales ou de spa. Pourront être évoquées les méthodes classiques, méthodes normalisées, ou de détection rapide (kit) ou méthodes PCR avec performances et comparatif éventuel de ces méthodes.

THEME II : APPLICATION DE CES MÉTHODES AUX CONTRÔLES DES EAUX Les sujets suivants sont prévus :

- Réglementation : évolution actuelle et future. Bilan du contrôle sanitaire surtout bactériologique des eaux dans les A.R.S.

La sécurité sanitaire des eaux de baignades aménagées et de piscines publiques est encadrée par le Code de la Santé Publique (Décret du 07 avril 1981, transposition en droit français de la directive 76/160/CEE et articles L. 1332-1 à L. 1332-4 et D. 1332-1 à D. 1332-19 du CDS).

Ces articles fixent les normes d'hygiène et de sécurité applicables aux piscines et baignades aménagées et les conditions dans lesquelles l'état assure (via les ARS) le contrôle sanitaire des piscines et baignades recevant du public. Ce contrôle sanitaire des piscines et baignades aménagées vise à vérifier la qualité de l'eau et le respect des règles d'hygiène. Une directive européenne Directive 2006/7/CE du Parlement européen et du Conseil du 15 février 2006 concernant la gestion de la qualité des eaux de baignade, modifie la gestion des risques liés à certaines catégories de baignade. Par ailleurs, une directive européenne, Directive 2006/7/CE du Parlement européen et du Conseil du 15 février 2006 concernant la gestion de la qualité des eaux de baignade, modifie la gestion des risques liés à certaines catégories de baignade.

La réglementation nationale ne s’applique pas aux piscines privées (non contrôlées), et ne prend pas en compte les spécificités des piscines ludiques (bassin à vague, à jets, à remous, jacuzzi, etc.) en plein développement ces dernières années, ni des nouvelles baignades artificielles plus ou moins « naturelles » ou « écologiques ». On peut s’interroger sur les risques sanitaires liées à ce type d'aménagements non couvert par la réglementation, recevant du public parfois en surnombre et utilisant des eaux de surface, des eaux souterraines ou des eaux de mer, soumises éventuellement à des traitements chimiques (floculation, désinfection) ou « biologiques » (filtration, oxygénation, plantes, etc.).

Réglementation en projet au niveau de Bruxelles pour l’eau potable 
- Maladies en lien avec la fréquentation des piscines, publiques ou privées, Hygiène des baigneurs avant leur entrée dans le bain.

\section{- Piscines Thermales. Spa. Eaux Récréatives :}

Contrôles : Préventions ; Entretien ; Contraintes médicales et propriétés thérapeutiques.

- Contrôles des Eaux potables et des Eaux embouteillées :

Le contrôle sanitaire, le contrôle du producteur en production des eaux potables (distribution publique ou eaux embouteillées) de la ressource au produit fini.

\section{- Désinfection des piscines publiques :}

Efficacité spécifique en microbiologie

- Risques sanitaires pour les professionnels des piscines :

Maîtres nageurs et nageurs de compétition.

- Piscines privées et risques sanitaires associés :

Gestion et qualité microbiologique lors de l'entretien, surdosage en désinfectant, etc.

- Piscines de grands immeubles ou de résidences pouvant recevoir éventuellement des baigneurs venus d'ailleurs. Doivent-elles être soumises à la réglementation et aux contrôles réguliers des ARS ?

- Baignades écologiques : conception, gestion, qualité sanitaire des eaux, suivi du fonctionnement,

- Nouveaux types de piscines ludiques ou thermoludiques :

Vagues, jets, etc. : suivi de qualité.

- Paramètres émergents :

Parasites, amibes, papillomas virus responsables de l'apparition des verrues, et incidences sanitaires.

\section{Le Président Gilles Husson}

